\title{
An Inadvertent Peripheral Arteriovenous Malformation Cannulation
}

\author{
Sourav Burman ${ }^{1}$ Charu Mahajan ${ }^{1} \quad$ Indu Kapoor ${ }^{1}$ \\ ${ }^{1}$ Department of Neuroanaesthesiology and Critical Care, \\ Neurosciences Centre, All India Institute of Medical Sciences, \\ New Delhi, India
}

J Neuroanaesthesiol Crit Care:2021;8:72-73

The incidence of accidental arterial cannulation and injection varies from 1 in 56,000 to 1 in 3,440. ${ }^{1}$ Many cases of accidental arterial cannulation and injection have been reported in literature, but a seemingly simple peripheral venous cannulation landing in a preformed arteriovenous malformation $(A V M)$ is of special interest and has not been reported earlier. After obtaining written informed consent from the patient, we report such a rare case of accidental AVM cannulation in which its prompt recognition prevented any further complication. A 22-year-old woman, known case of hydrocephalous, presented to the operating room for endoscopic third ventriculostomy. A 22-gauge cannula was already in situ, just above the wrist on the radial side of the forearm. As per the standard protocol, all monitors were attached and an infusion of normal saline was started through peripheral intravenous cannula. Immediately, we noticed a profuse backflow of blood in the intravenous line. We checked the force of backflow even by attaching an empty 2-mL syringe to it, which got rapidly filled by backpressure. On transducing the pressure, a distinct arterial waveform could be appreciated but with low mean pressure. The blood gas analysis report revealed partial pressure of oxygen: $77 \mathrm{~mm} \mathrm{Hg}$, partial pressure of carbon dioxide: $48 \mathrm{~mm} \mathrm{Hg}$, arterial oxygen saturation: $88 \%$ at fraction of inspired oxygen: 0.4 , end-tidal carbon dioxide: $30 \mathrm{~mm} \mathrm{Hg}$, and pulse oximetry oxygen saturation: 100\%. These values were indicative of mixed arteriovenous sample. We secured another intravenous access for carrying out surgery. After the tracheal intubation, standard anesthesia technique was followed for maintenance of anesthesia, and the surgery proceeded uneventfully. To seek the reason for these abnormal findings, we used an ultrasound to insonate the area where the cannula was placed. We could distinctly appreciate an aberrant connection between an artery and vein on long-axis view (-Fig 1A). The findings were confirmed by pulse wave Doppler study, which showed arterial and venous waveforms at respective sites (-Fig 1B). After scanning the area, we removed the cannula immediately. In the postoperative period, we observed the left hand for development of any complications.

Published online June 26, 2020
DOI https://doi.org/ $10.1055 / \mathrm{s}-0039-1692594$ ISSN 2348-0548.
Address for correspondence Charu Mahajan, MD, DM, Department of Neuroanaesthesiology and Critical Care, Neurosciences Centre, All India Institute of Medical Sciences, New Delhi 110029, India (e-mail: charushrikul@gmail.com).

In the operating room, an accidental arterial cannulation is suspected by bright red color of the blood, pulsatile flow, and an arterial blood gas (ABG) analysis. In our case, there was a good backflow even from the small-caliber 22G cannula, but $A B G$ report showed a mixed sample. Even pressure transduction could not confirm that it was an arterial placement. The possibility of an AVM could not be ruled out, though there was no palpable thrill/bruit or any such prior history. In an AVM, there is often a nidus interposed between the feeding arteries and draining veins. The nidus is a convoluted, densely packed, and poorly differentiated blood vessel with a very low resistance bed. ${ }^{2}$ On scanning the arteriovenous anatomy with an ultrasound, we were able to discover a distinct communication between the arterial and venous channel. The cannula tip could be in the venous end of the nidus, which was probably the reason of a low-pressure flow of the vascular bed. The pulsed wave Doppler study showed attenuated but pulsatile flow at the abnormal communication channel. The incidence of AVM formation secondary to peripheral cannulation is less than $0.003 \%{ }^{3}$ There was no history of trauma, past cannulation, or surgery of the left hand. As the patient was completely asymptomatic, it was decided not to carry out

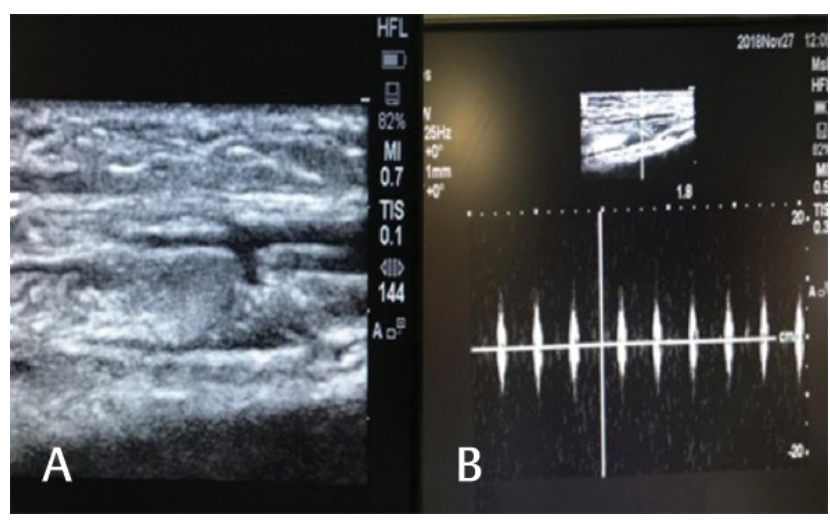

Fig. 1 (A) Ultrasonographic long-axis image showing a communication between the artery and the vein. (B) Pulse wave Doppler showing arterial waveform.

(C)2020. Indian Society of Neuroanaesthesiology and Critical Care. This is an open access article published by Thieme under the terms of the Creative Commons Attribution-NonDerivative-NonCommercial-License, permitting copying and reproduction so long as the original work is given appropriate credit. Contents may not be used for commercial purposes, or adapted, remixed, transformed or built upon. (https://creativecommons.org/licenses/by-nc-nd/4.0/).

Thieme Medical and Scientific Publishers Pvt. Ltd. A-12, 2nd Floor, Sector 2, Noida-201301 UP, India 
angiography. The timely detection and subsequent removal of cannula prevented development of complications.

Thus, the point of care, "ultrasound" proved its mettle to prevent a complication from occurring. Accidental cannulation of such rare vascular malformations can result in a diagnostic dilemma, and ultrasound can be an impeccable tool that should be used at the slightest suspicion. There is also a word of caution that drugs administered through such lines may result in catastrophic consequences, so vigilance is of utmost importance.

\section{References}

1 Sen S, Chini EN, Brown MJ. Complications after unintentional intra-arterial injection of drugs: risks, outcomes, and management strategies. Mayo Clin Proc 2005;80(6):783-795

2 Cil BE, Akmangit I, Peynircioğlu B, Karçaaltincaba M, Cekirge S. Iatrogenic femoral arteriovenous fistula: endovascular treatment with covered stent implantation and 4-year follow-up. Diagn Interv Radiol 2006;12(1):50-52

3 Yakes WF. Endovascular management of high-flow arteriovenous malformations. Semin Intervent Radiol 2004;21(1):49-58

Conflict of Interest

None declared.

\title{
(9) (1) $\ominus \circledast$
}

Correspondence

\section{Treating an International Patient: An Uncommon Experience}

\author{
Barkha Bindu ${ }^{1}$ Harsh Sapra ${ }^{1}$ Vasudha Singhal ${ }^{1}$ \\ ${ }^{1}$ Department of Neuroanaesthesia and Critical Care, Medanta-The \\ Medicity, Gurugram, Haryana, India
}

J Neuroanaesthesiol Crit Care:2021;8:73-74

We felt relieved when we discharged our patient home, after a stay of 2 months at our hospital. It was as much a relief for us, as it was for the patient. Over the preceding 2 months, we had repeatedly felt lost regarding the medicolegal implications of treating the patient.

Two months back, a middle-aged European citizen was admitted to our neuro intensive care unit (NICU). He was flying alone on a 14-hour long international flight, with neither origin nor destination in India. He suffered a generalized tonic-clonic seizure on-board and the flight made an emergency landing. He was deboarded and brought to our hospital, accompanied by airport personnel who completed the admission formalities. When admitted to NICU, the patient was postictal. For the next 2 days in ICU, he was aggressive, occasionally cooperating with our instructions, and repeatedly expressing displeasure over being admitted. Treatment was initiated based on initial investigations and whatever little discussion was possible with him. The international help

Published online

July 9,2020
DOI https://doi.org/

$10.1055 / \mathrm{s}-0039-1693077$

ISSN 2348-0548.
Address for correspondence Barkha Bindu, MD, DNB, DM, Department of Neuroanaesthesia and Critical Care, Medanta-The Medicity, Gurugram 122001, Haryana, India (e-mail: barkhabindu@gmail.com).

desk (IHD) at our hospital informed the embassy about the patient's condition and admission. The embassy contacted his family, who were unwilling to visit. On day 3 , when the patient developed respiratory distress and needed intubation, obtaining consent for intubation proved to be a difficult task. There was no family member available, nor were embassy officials available for consent. The embassy contacted the patient's family who were still reluctant to come. After trying for an hour and consulting both embassy and hospital management, we had to intubate the patient without written informed consent due to deteriorating clinical condition. We only had telephonic assurance from the embassy that we could do whatever was medically necessary for the patient. A minor bedside diagnostic procedure was then planned. We again performed the procedure without written informed consent. However, after detailed discussion with hospital management, medical superintendent (MS) of the hospital later signed the consent forms. Subsequently, the patient gradually improved and was 